\title{
Article
}

\section{Light Hydrocarbons Adsorption Mechanisms in Two Calcium-based Microporous Metal Organic Frameworks}

Anna M. Plonka, Xianyin Chen, Hao Wang, Rajamani Krishna, Xinglong Dong, Debasis Banerjee, William R. Woerner, Yu Han, Jing Li, and John B. Parise

Chem. Mater., Just Accepted Manuscript • DOI: 10.1021/acs.chemmater.5b03792 • Publication Date (Web): 25 Jan 2016

Downloaded from http://pubs.acs.org on February 1, 2016

\section{Just Accepted}

"Just Accepted" manuscripts have been peer-reviewed and accepted for publication. They are posted online prior to technical editing, formatting for publication and author proofing. The American Chemical Society provides "Just Accepted" as a free service to the research community to expedite the dissemination of scientific material as soon as possible after acceptance. "Just Accepted" manuscripts appear in full in PDF format accompanied by an HTML abstract. "Just Accepted" manuscripts have been fully peer reviewed, but should not be considered the official version of record. They are accessible to all readers and citable by the Digital Object Identifier (DOI®). "Just Accepted" is an optional service offered to authors. Therefore, the "Just Accepted" Web site may not include all articles that will be published in the journal. After a manuscript is technically edited and formatted, it will be removed from the "Just Accepted" Web site and published as an ASAP article. Note that technical editing may introduce minor changes to the manuscript text and/or graphics which could affect content, and all legal disclaimers and ethical guidelines that apply to the journal pertain. ACS cannot be held responsible for errors or consequences arising from the use of information contained in these "Just Accepted" manuscripts. 


\section{INTRODUCTION}

For natural gas purification $\mathrm{CO}_{2}$ and light hydrocarbons are removed from methane in order to reduce $\mathrm{CO}_{2}$-induced pipeline corrosion and produce high-purity gases for energy and other industrial applications. ${ }^{1}$ The purified methane obtained from natural gas is an alternative to gasoline or diesel automobile fuels. ${ }^{2}$ Furthermore, natural gas is the main source of ethane, which is the second largest component after methane, ranging from 0.7 to 6.8 volume percent. ${ }^{3}$ Ethane is the main feedstock for ethylene production, which in turn serves as the primary building block of polyethylene-based materials. ${ }^{4}$ Thus effective separation of light hydrocarbon gases $\left(\mathrm{C}_{1}-\mathrm{C}_{2}\right)$ is important for the petroleum industry and influences the price and availability of plastics, used routinely in our daily lives. Currently $\mathrm{CO}_{2}$ and light hydrocarbon fractions of natural gas are separated through energy intensive cryogenic distillation; separation using solid state adsorbents capable of operating in higher temperatures is proposed as a more economical alternative. ${ }^{5}$ Indeed several classes of porous solid state materials have been tested for industrially important gaseous hydrocarbon separation (e.g. $\mathrm{C}_{2}, \mathrm{C}_{3}, \mathrm{C}_{4}$ ) with encouraging results. ${ }^{6-8}$ Zeolites $5 \mathrm{~A}$ and $13 \mathrm{X}$ can be used for the propylene/propane separation as reported by Järvelin and Fair. ${ }^{6}$ Linear and branched hydrocarbon mixtures such as nbutane/i-butane or xylene isomers can be separated with MFItype zeolites, with the reported separation factor between 20 60 for n-butane and over 600 for xylene. ${ }^{7}$ Silver exchanged porous aromatic framework $\mathrm{PAF}-1-\mathrm{SO}_{3} \mathrm{H}$ effectively separates $\mathrm{C}_{2}$ hydrocarbons, as reported by Ma and coworkers. ${ }^{8}$
Microporous MOFs, formed by metal atoms or atom clusters connected by organic ligands to form infinite networks, have sorption properties comparable or superior to benchmark solid state adsorbents. ${ }^{9-13}$ MOFs possess seemingly limitless structural diversity, high flexibility, and in some cases easily modified frameworks that allow tuning for specific functions. ${ }^{14,15}$ Possible industrial applications of MOFs include gas storage, gaseous and molecular separation, catalysis or chemical sensing. ${ }^{10,16-23}$ Selected MOF-based solid state adsorbents are utilized for various hydrocarbon separations. ${ }^{5}$ For example, ZIF-7 and RPM-3-Zn [ZIF: Zeolitic Imidazole Framework, $\mathrm{Zn}(\mathrm{phim})_{2}$; phim: benzimidazole, RPM: Rutgers Porous Material; $\quad \mathrm{Zn}_{2}(\mathrm{bpdc})_{2}$ (bpee); bpdc: 4,4'biphenyldicarboxylate, bpee: 1,2-bipyriylethylene] can separate $\mathrm{C}_{2}-\mathrm{C}_{4}$ hydrocarbons, due to the gate opening effect, happening at different pressures for smaller and larger molecules. ${ }^{24,25}$ MOF-5 $\left[\mathrm{Zn}_{4} \mathrm{O}(\mathrm{bdc})_{3}\right]$ separates methane from n-butane, and linear from branched alkanes. ${ }^{26,27}$ HKUST-1 [HKUST: Hong Kong University of Science and Technology; $\mathrm{Cu}_{3}(\mathrm{btc})_{2}$; btc: 1,3,5-benzenetricarboxylate] separates o-, $\mathrm{m}$ and p-xylenes. ${ }^{28}$

Experimental gas adsorption studies of MOFs usually focus on gas isotherms measurments that, while providing the necessary information on the overall gas uptake and framework behavior upon gas loading, yield limited information on gas adsorption mechanism. Understanding the key atom-atom interactions responsible for high gas selectivity provides a means to discriminate between possible materials for industrial applications like natural gas purification. Long and coworkers recently reported the neutron diffraction study on $\mathrm{C}_{2}-\mathrm{C}_{3}$ 
hydrocarbon adsorption on Fe-MOF-74, which selectively adsorbs olefins over paraffins. ${ }^{29}$ The selectivity originates in the stronger interaction between unsaturated than saturated hydrocarbons with bare $\mathrm{Fe}(\mathrm{II})$ sites, as determined from the distances between adsorbate and the open metal site. ${ }^{29}$ Kitagawa and coworkers used in-situ synchrotron powder X-ray diffraction (PXRD) techniques to discover the structural reasons for a high uptake of acetylene, and they located sorption sites in a small pore $\mathrm{MOF}-\mathrm{Cu}_{2}(\mathrm{pzdc})_{2}(\mathrm{pyz})$ [pzdc $=$ pyrazine 2,3-dicarboxylate, pyz $=$ pyrazine]. ${ }^{30}$ Further, MIL-47 $[\mathrm{V}(\mathrm{O})(\mathrm{bdc})]$ and MIL-53-Cr can separate xylene isomers, with MIL-47 displaying higher values of selectivity due to entropic effects. $^{31}$ The structure model of xylene:MIL-47 adduct was determined by fitting it to synchrotron PXRD data with the Rietveld refinement technique. ${ }^{31}$

Single crystal X-ray diffraction has been used to characterize adsorption mechanisms of $\mathrm{C}_{1}-\mathrm{C}_{2}$ hydrocarbons in several MOFs, but only a very limited number of those studies are reported to date. ${ }^{32} \mathrm{Kim}$ and coworkers characterized the methane adsorption mechanism in $\mathrm{Zn}_{2}(\mathrm{bdc})_{2}$ (dabco) $[\mathrm{bdc}=1,4-$ benzenedicarboxylate, dabco $=1$,4-diazabicyclo(2.2.2)octane], as well as the acetylene adsorption on $\mathrm{Mg}$ and $\mathrm{Mn}$ formates. ${ }^{33,34}$ The adsorption sites of various gases, including methane and acetylene in $\mathrm{S} \mathrm{Sc}_{2}(\mathrm{bdc})_{3}$ framework were reported by Miller et $a l^{35}$ Finally, Zhang and Chen reported acetylene and carbon dioxide adsorption mechanism in MAF-2 (MAF: metal azolate framework; $\mathrm{Cu}(\mathrm{etz})$; Hetz: 3,5-diethyl-1,2,4triazole), with a maximum acetylene uptake some 40 times higher than for acetylene in a gas cylinder at $1.0-1.5 \mathrm{bar}$, due to the optimal geometry of the framework pores. ${ }^{36}$

Among the diverse range of porous MOFs reported so far, those containing biocompatible metals like calcium and magnesium are of special interest. The low toxicity and Earth abundance of $\mathrm{Ca}$ - and $\mathrm{Mg}$-based MOFs, relative to first-row transitional metals or lanthanide metals-based MOF analogues, may be especially beneficial in potential industrial applications. ${ }^{37-39}$ We have recently reported several calcium MOFs with interesting properties. ${ }^{40-43}$ Herein, we report hydrocarbon adsorption mechanism determined from single crystal X-ray diffraction on two calcium-based MOFs - SBMOF-1 [Ca(sdb); sdb: 4,4'-sulfonyldibenzoate] and a novel material SBMOF-2 [Ca(tcpb); tcpb: 1,2,4,5-tetrakis(4carboxyphenyl)benzene]. Their $\mathrm{C}_{2} / \mathrm{C}_{1}$ selectivity was determined from the ideal adsorbed solution theory (IAST) calculations, supported by transient breakthrough calculations. ${ }^{44,45}$ Since the examples related to the $\mathrm{C}_{2} \mathrm{H}_{\mathrm{n}}$-framework interaction determined by single crystal diffraction method are scarce, the detailed structural insights gained here will help design further gas-selective solids of this type.

SBMOF-1 is a porous metal organic framework, with moderate surface area of $145 \mathrm{~m}^{2} / \mathrm{g}$ and calculated porosity of $16 \%$ (PLATON). ${ }^{40,46}$ After removal of solvent water SBMOF-1 does not adsorb water from the air and remains crystalline after exposure to $75 \%$ relative humidity for at least 2 months of storage and-(Fig. S1). Structurally SBMOF-1 is composed of $\mathrm{Ca}$ metal centers, coordinated by oxygen atoms in octahedral configuration and $\mathrm{v}$-shaped $\mathrm{sdb}$ organic linkers, forming diamond-shaped 1-D channels along $b$ direction (Fig. 1). After removal of solvent water, the framework of SBMOF-1 undergoes a structural rearrangement involving the rotation of the sdb linker. ${ }^{40}$ Our previous study showed that SBMOF-1 is
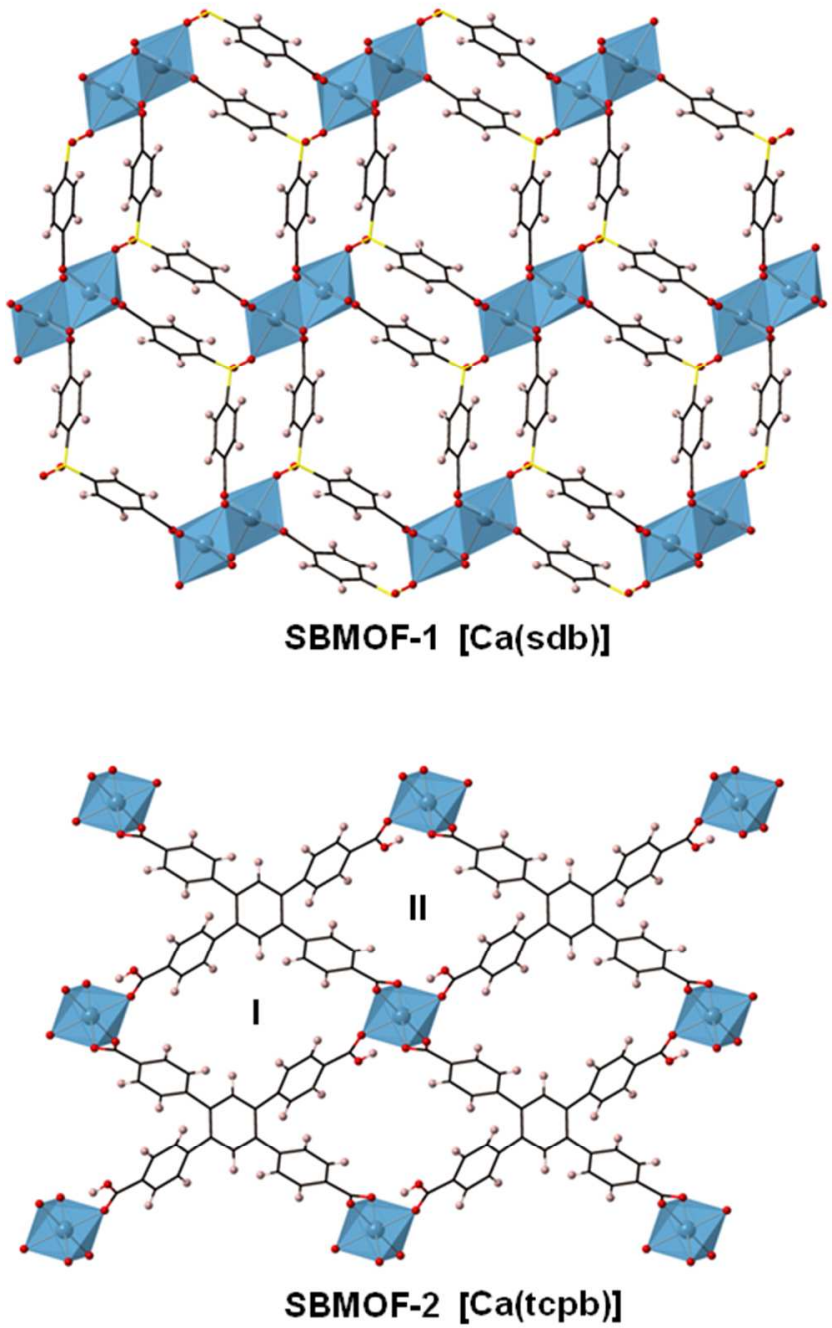

Figure 1. Polyhedral representation of the (a) SBMOF-1 and (b) SBOF-2 structures, as seen in [010] and [100], respectively. SBMOF-2 displays two crystallographically different types of channels, designated on the figure as I and II. Blue polyhedra represent $\mathrm{Ca}$, red spheres $-\mathrm{O}$, black wire $-\mathrm{C}$, yellow wire $-\mathrm{S}$ and pink spheres $-\mathrm{H}$.

selective towards $\mathrm{CO}_{2}$ over $\mathrm{N}_{2}$ and the selectivity arises from the geometry of the pores, where the $\mathrm{CO}_{2}$ molecule interact with two phenyl rings at a time through a quadrupole- $\pi$ interaction. $^{47}$

SBMOF-2 is a novel material that we recently reported, which shows high $\mathrm{Xe} / \mathrm{Kr}$ selectivity of about 10 at $298 \mathrm{~K}$ and the surface area of $195 \mathrm{~m}^{2} / \mathrm{g}$, stable in both air and humidity (Fig. S2). ${ }^{43}$ Structurally it is based on isolated $\mathrm{CaO}_{6}$ octahedra, connected by a half-deprotonated tcpb linkers into a threedimensional framework, with diamond-shaped channels running along $a$ (Fig. 1). SBMOF-2 has a permanent porosity of $25.6 \%$ (PLATON) $^{46}$ and contains two types of crystallographically different channels (type I and II). ${ }^{43}$ The channels have walls built with phenyl rings, and additionally the channels of the type II contain polar -OH groups. Both the phenyl rings and oxygen atoms serve as strong adsorption sites for $\mathrm{C}_{2} \mathrm{H}_{n}$ molecules. Similarly to SBMOF-1, after removal of the native solvent water, SBMOF-2 does not saturate with the water vapor from the atmosphere as evident for thermogravimetric and diffraction experiments. ${ }^{43}$ 

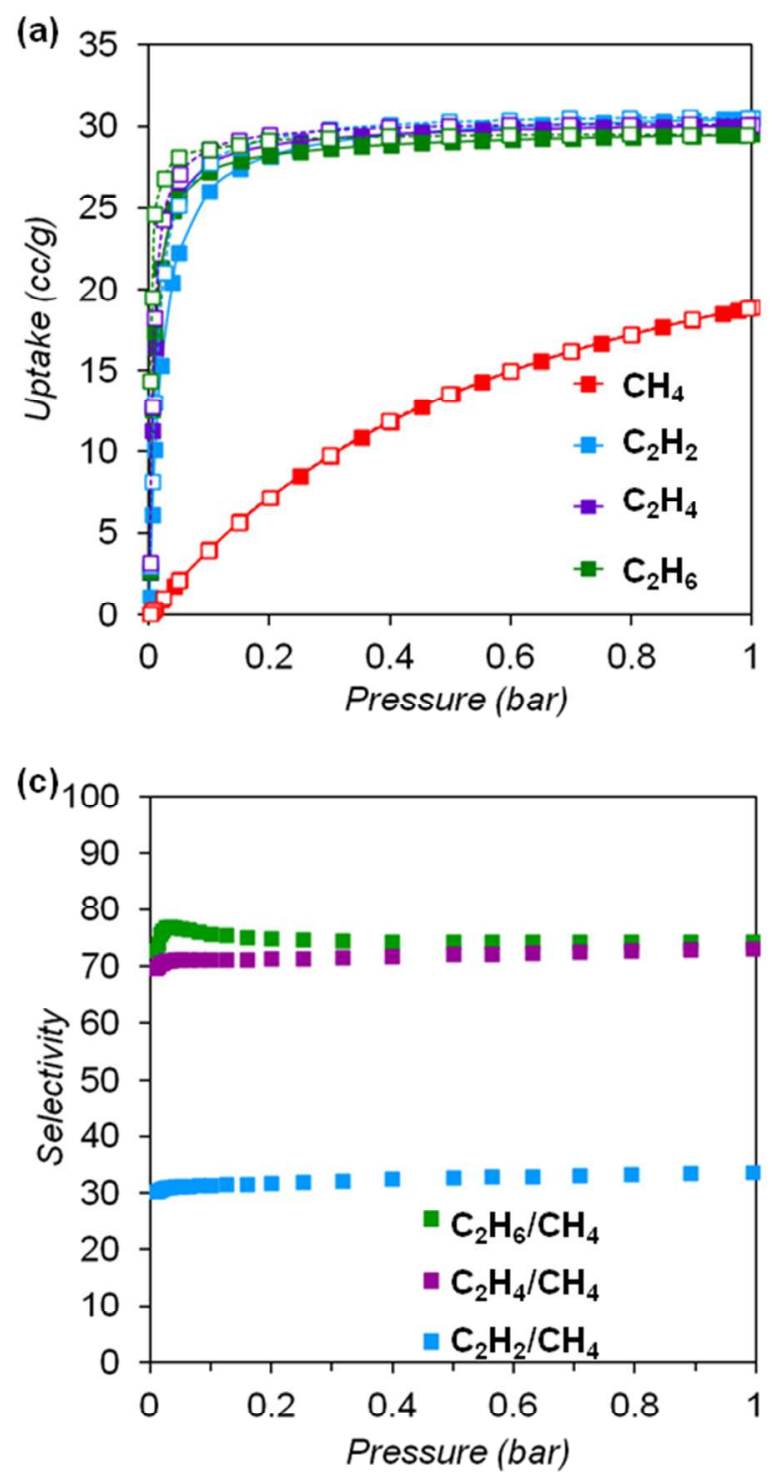
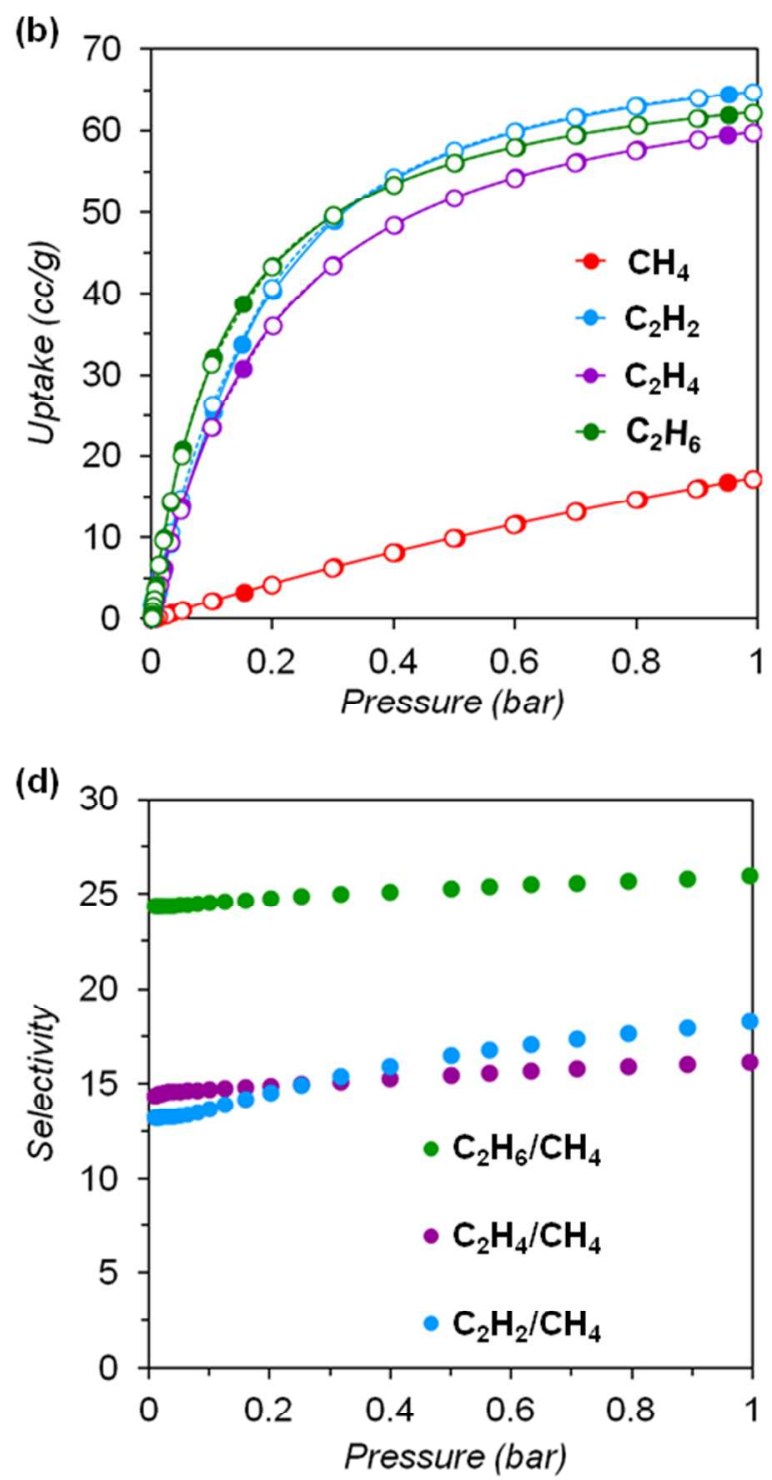

Figure 2. Gas adsorption isotherms of $\mathrm{C}_{1}-\mathrm{C}_{2}$ hydrocarbons at $298 \mathrm{~K}$ for (a) SBMOF-1 and (b) SBMOF-2; calculated $\mathrm{C}_{2} \mathrm{H}_{\mathrm{n}} / \mathrm{CH}_{4}$ selectivity at $298 \mathrm{~K}$ for (c) SBMOF-1 and (d) SBMOF-2.

\section{EXPERIMENTAL SECTION}

\subsection{Synthesis and Sample Activation}

SBMOF-1 and SBMOF-2 were synthesized according to the previously reported procedures under solvothermal conditions. ${ }^{40,43}$ Starting materials include calcium chloride $\left(\mathrm{CaCl}_{2}, \quad 96 \%\right.$, Acros-Organics), 1,2,4,5-Tetrakis(4carboxyphenyl)benzene acid [ $\mathrm{H}_{2}(\mathrm{tcpb}), 98 \%$, Sigma Aldrich], 4,4'-sulfonyldibenzoic acid [ $\mathrm{H}_{2}(\mathrm{sdb}), 98 \%$, Sigma-Aldrich] and ethanol (95\%, Fisher Scientific) and were used without further purification.

For the synthesis of SBMOF-1 a mixture of $0.074 \mathrm{~g}(0.6$ mmoles) of $\mathrm{CaCl}_{2}$ and $0.198 \mathrm{~g}$ (0.6 mmoles) of $\mathrm{H}_{2} \mathrm{Sdb}$ was dissolved in 10 grams of ethanol and stirred for 3 hours to achieve homogeneity. The solution was placed in an oven in $453 \mathrm{~K}$ and held at $453 \mathrm{~K}$ for 4 days. Products of the reaction were the colorless, prism-shaped crystals, which after recovering from the reaction were filtered and washed with ethanol (yield: $50 \%, 0.100 \mathrm{~g}$ ).
For the synthesis of SBMOF-2 a mixture of $0.027 \mathrm{~g}(0.25$ mmoles) of $\mathrm{CaCl}_{2}$ and $0.03 \mathrm{~g}$ ( 0.05 mmoles) of $\mathrm{H}_{2}(\mathrm{tcpb})$ was dissolved in 12 grams of ethanol and stirred for 2 hours to achieve homogeneity. The resultant solution was heated at 373 $\mathrm{K}$ for 3 days in the oven. Colorless prism-shaped crystals were recovered as a product and washed with ethanol. The yield was $\sim 50 \%, 0.02 \mathrm{~g}$.

As-synthesized SBMOF-1 and SBMOF-2 contain uncoordinated, disordered water molecules inside the channels. Water molecules come from the $95 \%$ ethanol solvent and the adsorbed moisture on the $\mathrm{CaCl}_{2}$ reactant. For the removal of the solvent (activation) SBMOF-1 and SBMOF-2 were heated to 563 and $513 \mathrm{~K}$, respectively and held in vacuum for 12 hours. ${ }^{40,43}$

\subsection{Gas Adsorption}

SBMOF-1 and SBMOF-2 were tested for $\mathrm{C}_{1}-\mathrm{C}_{2}$ hydrocarbon gases adsorption at 273/278, 288, $298 \mathrm{~K}$ and the pressures up to 1 bar (Fig. 2, Figs. S3-S13). Additionally, adsorption of 

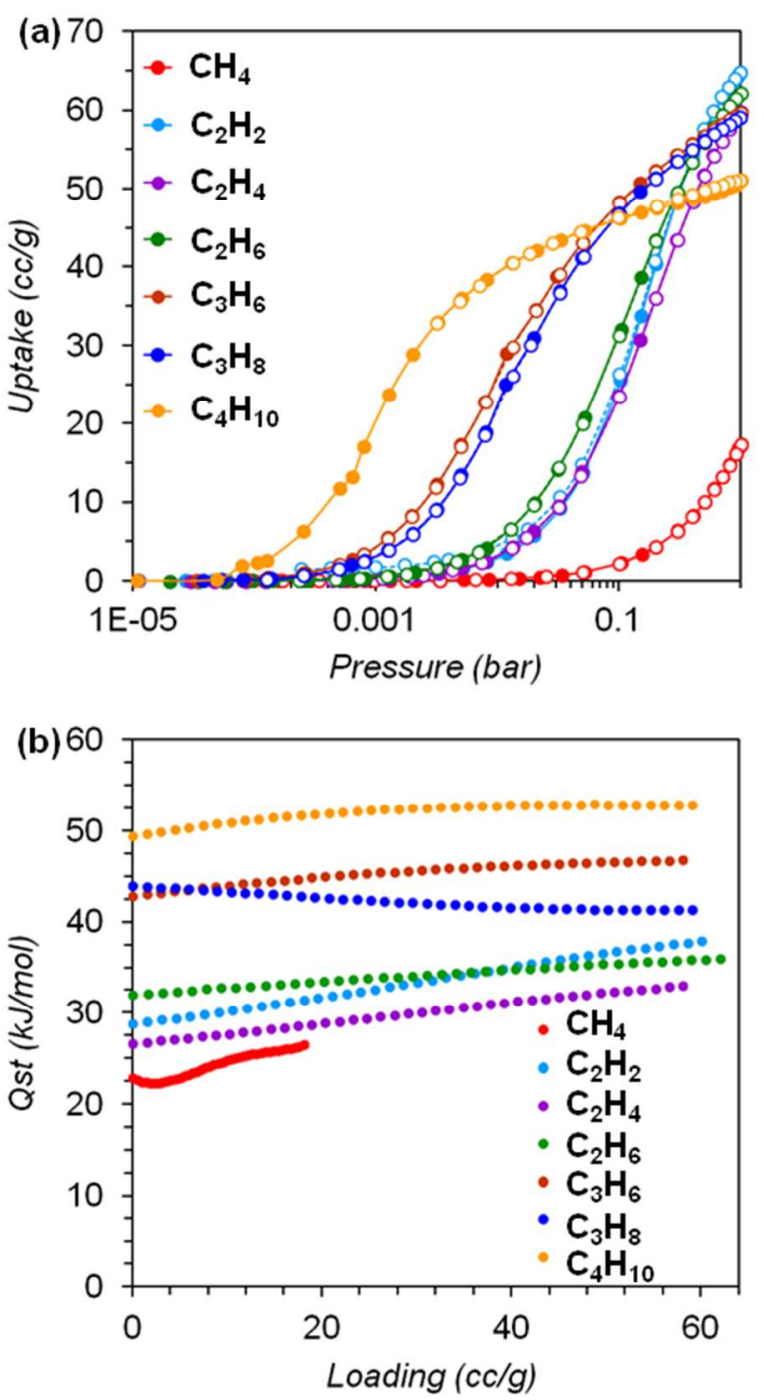

Figure 3. (a) Gas adsorption isotherms of $\mathrm{C}_{1}-\mathrm{nC}_{4}$ hydrocarbon gases at $298 \mathrm{~K}$ for SBMOF-2; (b) Isosteric heat of adsorption for $\mathrm{C}_{1}-\mathrm{nC}_{4}$ hydrocarbon gases on SBMOF-2 calculated with the Virial method.

propane, propylene and n-butane was measured for SBMOF-2 and the results are shown in Figure 3a.

Gas adsorption studies of the materials described herein were performed with a volumetric gas sorption analyzer (Autosorb-1-MP, Quantachrome Instruments) with the ultra-high purity gases (99.999\%). Initially, approximately $100 \mathrm{mg}$ of the sample was activated under vacuum, for 12 hours, and the weight was measured before and after activation to ensure the full solvent removal. After cooling, isotherms were collected at three different temperatures in the pressures up to 1 bar. The activation step was repeated for the same sample between each run.

Single-component hydrocarbon adsorption isotherms were fitted with the DSLF model to enable the application of IAST in simulating the performance of SBMOF-1 and SBMOF-2 under a mixed component gas (see Supplementary Information). ${ }^{44,48}$ The fitting parameters of DSLF equation as well as the correlation coefficients (R2) are listed in Table S1. Figures S14-15 show experimental and fitted isotherms for $\mathrm{C}_{1}-\mathrm{C}_{2}$ hydrocarbon gases for SBMOF-1 and SBMOF-2 at $298 \mathrm{~K}$.

\subsection{Transient breakthrough}

We performed transient breakthrough simulations using the simulation methodology described in the literature. ${ }^{45}$ For the breakthrough simulations, the following parameter values were used: length of packed bed, $L=0.3 \mathrm{~m}$; voidage of packed bed, $\varepsilon=0.4$; superficial gas velocity at inlet, $u=0.04 \mathrm{~m} / \mathrm{s}$. The simulation results for transient breakthrough are presented in terms of a dimensionless time $\tau$, defined by dividing the actual time, $t$, by the characteristic time, $\frac{L \varepsilon}{\tau}$.

The supplementary breakthrough experiment was conducted using a lab-scale fix-bed reactor at $296 \mathrm{~K}$. In a typical experiment, $690 \mathrm{mg}$ of SBMOF-1 powder was activated in high vacuum at $563 \mathrm{~K}$ for $10 \mathrm{~h}$. Then the material was packed into a quartz column $(5.8 \mathrm{~mm}$ I.D. $\times 150 \mathrm{~mm})$ with silane treated glass wool filling the void space. A helium flow $\left(1 \mathrm{~cm}^{3} \mathrm{~min}^{-1}\right)$ was used to purge the adsorbent. The flow of $\mathrm{He}$ was then turned off while a gas mixture of $\mathrm{CH}_{4} / \mathrm{C}_{2} \mathrm{H}_{2} / \mathrm{C}_{2} \mathrm{H}_{4} / \mathrm{C}_{2} \mathrm{H}_{6}$ $(25: 25: 25: 25, \mathrm{v} / \mathrm{v})$ at $1 \mathrm{~cm}^{3} \mathrm{~min}^{-1}$ was allowed to flow into the column. The effluent from the column was monitored using an online mass spectrometer (MS). ${ }^{49}$

\subsection{Single Crystal XRD with Adsorbed Hydrocarbon Gas- es}

For the gas loading, activated crystals of SBMOF-1 and SBMOF-2 were placed in a three-neck flask with ethane, ethylene or acetylene flowing into the flask, and kept for 2 hours. Further the crystals were coated with Paratone ${ }^{\circledR}$ oil, while keeping the gas flowing to maintain 1 bar conditions. Crystals of the $\mathrm{C}_{2} \mathrm{H}_{\mathrm{n}}$-loaded SBMOF-1 and SBMOF-2 suitable for the single crystal X-ray diffraction were selected from the bulk using polarizing microscope to determine crystal quality. Reflections for the compounds SBMOF-1: $\mathrm{C}_{2} \mathrm{H}_{2}$, SBMOF-1: $\mathrm{C}_{2} \mathrm{H}_{4}$, SBMOF-2: $\mathrm{C}_{2} \mathrm{H}_{2}$ and SBMOF-2: $\mathrm{C}_{2} \mathrm{H}_{4}$ were collected with $1^{\circ} \omega$ scans at $100 \mathrm{~K}$ using a four-circle kappa Oxford Gemini diffractometer $(\lambda=0.71073 / 1.54184 \AA)$. Raw intensity data were collected, integrated and corrected for absorption effects using CrysAlisPRO software. ${ }^{50}$ Reflections for SBMOF-1: $\mathrm{C}_{2} \mathrm{H}_{6}$ and SBMOF-2: $\mathrm{C}_{2} \mathrm{H}_{6}$ were collected at $100 \mathrm{~K}$ using a three-circle Bruker D8 diffractometer, equipped with an APEX II detector, with the X-ray wavelength $\lambda=0.41328 \AA$, using $0.5^{\circ} \varphi$ scans at APS ChemMatCars (sector 15) beamline. Raw intensity data were collected, integrated and corrected for absorption effects with the Apex II software suite. ${ }^{51}$

Structures of gas-loaded SBMOF-1 and SBMOF-2 were solved with direct methods using SHELXS-97 and refined with full-matrix least squares on $\mathrm{F}^{2}$ with SHELXTL-97 (Tables S2-S3). ${ }^{52,53}$ During structure solution atoms from the MOF framework were located first and refined with anisotropic displacement parameters. Hydrogen atoms were added to aromatic rings using geometrical constrains (HFIX command). After obtaining a satisfactory model of the framework, Fourier difference maps were calculated to locate the adsorbed gas molecules using WinGX suite (Fig. 4a). ${ }^{54}$ All gas molecules were located from the strong electron density peaks and refined with anisotropic displacement parameters (Fig. 4 b-c). The occupancy of the $\mathrm{C}$ atoms from the adsorbed gases was also refined. The $\mathrm{C}-\mathrm{C}$ distances in the hydrocarbon molecules were restrained to $1.20(1) \AA, 1.30(1) \AA$ and 1.47(1) $\AA$ for acetylene, ethylene and ethane, respectively. Hydrogen atoms on the hydrocarbon molecules were added with geometrical constrains. In most cases the $\mathrm{H}$ atoms were visible on the 
(a)

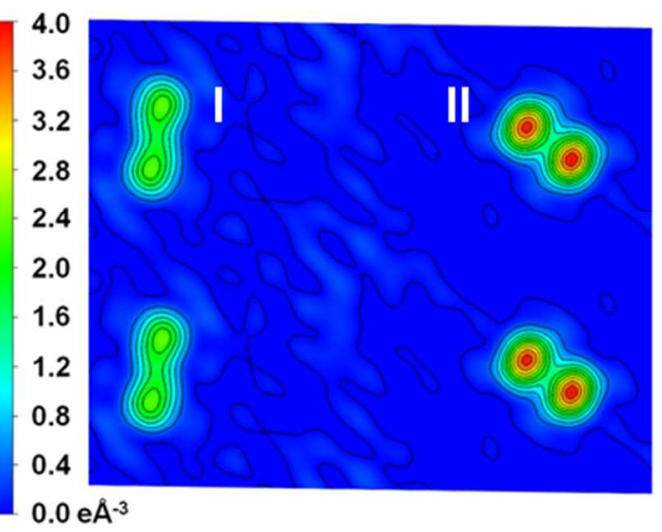

(b)

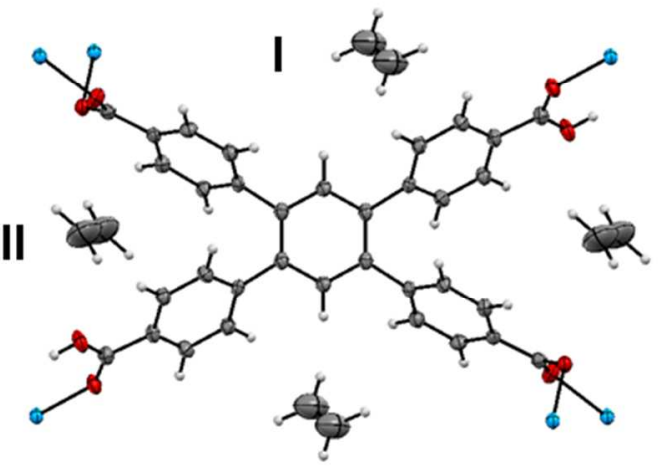

(c)

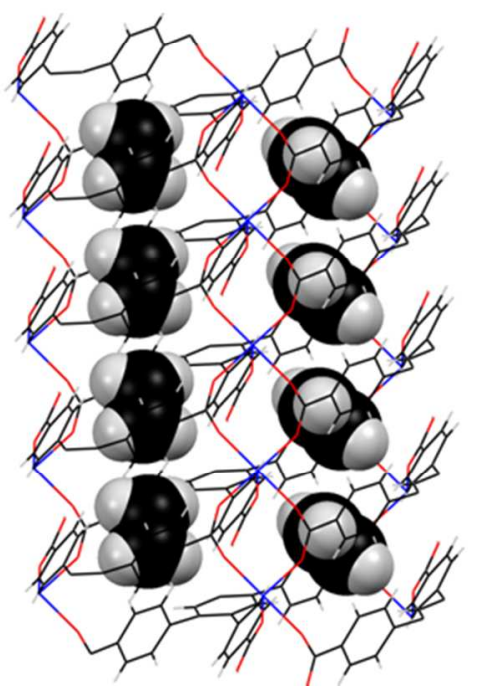

Figure 4. (a) differential Fourier electron density map, electron density on the left side indicates ethylene molecules adsorbed in channels of type I, on the right side - channels type I $^{64}$ (b) refined structure, atoms drawn at 50\% probability level, (c) structure of ethylene-loaded SBMOF-2, gas molecules shown at space filling mode, network as wireframe. Blue spheres/wire represent $\mathrm{Ca}$, red $-\mathrm{O}$, black $-\mathrm{C}$, grey $-\mathrm{H}$.

electron density maps. Full details of the structure determinations have been deposited with Cambridge Crystallographic Data Center under reference numbers: 14205800 - 1420585 and are available free of charge from CCDC.

\subsection{XRD-DSC}

Differential enthalpy of adsorption of hydrocarbon gases $\left(\Delta H, \mathrm{~kJ} / \mathrm{mol}_{\mathrm{MOF}}\right)$ was measured with differential scanning calo- rimetry (DSC) at $298 \mathrm{~K}$ via vacuum-swing experimental procedure for $\mathrm{C}_{1}-\mathrm{C}_{2}$ in SBMOF-1 and $\mathrm{C}_{1}-\mathrm{nC}_{4}$ in SBMOF-2.

The collection of DSC data was accompanied with in situ powder diffraction measurments (XRD-DSC), allowing for the evaluation of the structural changes simultaneously with measuring gas adsorption enthalpy. We previously used the XRD-DSC method to study $\mathrm{CO}_{2}$ adsorption in the presence of humidity in SBMOF-1 and other porous materials. ${ }^{47,55,56}$ Isosteric heat of adsorption values $\left(Q_{s t}, \mathrm{~kJ} / \mathrm{mol}_{\mathrm{GAS}}\right)$ were obtained through the relation $Q_{s t}=\Delta H / n_{i}\left(n_{i}=\right.$ moles of the gas $)$. Furthermore, $Q_{s t}$ for $\mathrm{C}_{1}-\mathrm{nC}_{4}$ hydrocarbons were calculated for SBMOF-2 material with the Virial method, ${ }^{10}$ and the values of $Q_{s t}$ obtained with DSC and Virial methods are in agreement (Table S4).

Powder XRD-DSC measurements were collected with a Rigaku Ultima IV diffractometer $(\mathrm{Cu} \mathrm{K \alpha} ; \lambda=1.5405 \AA)$ with a $\mathrm{D} /$ teX Ultra high speed one-dimensional position sensitive detector. Powder X-ray pattern were collected within a range $5^{\circ} \leq 2 \theta \leq 37^{\circ}$ (step size: $0.02^{\circ}$, counting time: $2 \mathrm{~s} / \mathrm{step}$ ). The DSC measurements were performed using $9-10.5 \mathrm{mg}$ of the sample in an aluminum crucible with an equal amount of $\mathrm{Al}_{2} \mathrm{O}_{3}$ in the reference crucible.

For the vacuum-swing experiments the sample was first heated to $563 \mathrm{~K}$ (SBMOF-1) or $523 \mathrm{~K}$ (SBMOF-2) under vacuum on the XRD-DSC stage, held at activation temperature for 5 to $10 \mathrm{~h}$ to ensure the activation, and then cooled to RT. Further the chamber was pressurized to 1 bar of hydrocarbon gas over the course of 15 seconds. After 120 (SBMOF-1) or 10 (SBMOF-2) minutes, when the DSC signal returned to the baseline, the chamber was evacuated to vacuum over the course of 15 seconds. In the case of SBMOF1 strong interaction between the adsorbate and the framework leads to an incomplete removal under experimental vacuum conditions; as a result the enthalpy values were calculated based on the averages of the exotherm of three different samples. In the case of SBMOF-2 all gases can be removed with vacuum and a total of 6 to 8 cycles was completed. During the first cycle XRD data were collected.

\section{RESULTS AND DISCUSSION}

SBMOF-1 shows moderate adsorption of $\mathrm{C}_{2} \mathrm{H}_{\mathrm{n}}$ gases at 298 $\mathrm{K}$; uptakes of $30.44,30.0$ and $29.5 \mathrm{~cm}^{3} / \mathrm{g}$ were measured for acetylene, ethylene and ethane, respectively. Methane is adsorbed at a lower amount than $\mathrm{C}_{2} \mathrm{H}_{\mathrm{n}}$ with the uptake of 18.85 $\mathrm{cm}^{3} / \mathrm{g}$ at $1 \mathrm{bar}, 298 \mathrm{~K}$ (Fig. 2a). The main difference between the adsorption of methane and $\mathrm{C}_{2} \mathrm{H}_{\mathrm{n}}$ is apparent when looking at the low pressure region of the isotherm. SBMOF-1 is saturated with $\mathrm{C}_{2} \mathrm{H}_{n}$ at a very low pressure; for example, the ethane uptake of $27.3 \mathrm{~cm}^{3} / \mathrm{g}$ at $0.1 \mathrm{bar}$ is equal to over $90 \%$ of the total uptake at 1 bar. For comparison, methane adsorption at $0.1 \mathrm{bar}\left(0.91 \mathrm{~cm}^{3} / \mathrm{g}\right)$ is equivalent to less than $5 \%$ of the total uptake at $1 \mathrm{bar}$, and is more than 30 times lower than the ethane uptake at this pressure. $Q_{s t}$ of $\mathrm{C}_{1}-\mathrm{C}_{2}$ hydrocarbons in SBMOF-1 is relatively high, ${ }^{5,29}$ with moderate differences between methane and $\mathrm{C}_{2} \mathrm{H}_{n}$ (Table 1). The difference in adsorption behavior and heats of adsorption between methane and $\mathrm{C}_{2} \mathrm{H}_{\mathrm{n}}$ could be explained by higher electrostatic and dispersion interactions with the pore surface, and thus higher affinity of SBMOF-1 towards $\mathrm{C}_{2}$ gases compared to small methane. ${ }^{5}$ The gas adsorption selectivity calculated with the IAST method shows the $\mathrm{C}_{2} \mathrm{H}_{6} / \mathrm{CH}_{4}$ selectivity of $74, \mathrm{C}_{2} \mathrm{H}_{4} / \mathrm{CH}_{4}$ 
Table 1. Hydrocarbon adsorption in SBMOF-1 and SBMOF-2, gas uptake measured with gas isotherms, $\Delta H$ and $Q_{s t}$ obtained trough DSC vacuum-swing experiments. ${ }^{45,52}$

\begin{tabular}{cccc|ccc}
\hline & \multicolumn{3}{c|}{ SBMOF-1 } & \multicolumn{3}{c}{ SBMOF-2 } \\
& $\begin{array}{c}\text { Uptake } \\
(\mathbf{w t} \%)\end{array}$ & $\boldsymbol{\Delta H}\left(\mathbf{k J} / \mathbf{m o l}_{\mathbf{M O F}}\right)$ & $\boldsymbol{Q}_{s t}\left(\mathbf{k J} / \mathbf{m o l}_{\mathbf{G A S})}\right.$ & $\begin{array}{c}\text { Uptake } \\
(\mathbf{w t} \%)\end{array}$ & $\boldsymbol{\Delta H}\left(\mathbf{k J} / \mathbf{m o l}_{\mathbf{M O F}}\right)$ & $\boldsymbol{Q}_{s t}\left(\mathbf{k J} / \mathbf{m o l}_{\mathbf{G A S}}\right)$ \\
$\mathbf{C H}_{\mathbf{4}}$ & 1.66 & $10(1)$ & $28(3)$ & 1.99 & $8.3(1)$ & $18.0(2)$ \\
$\mathbf{C}_{\mathbf{2}} \mathbf{H}_{\mathbf{2}}$ & 3.53 & $16.3(1)$ & $34.8(3)$ & 7.51 & $55.4(4)$ & $30.3(2)$ \\
$\mathbf{C}_{\mathbf{2}} \mathbf{H}_{\mathbf{4}}$ & 3.75 & $16.5(3)$ & $35.0(5)$ & 7.47 & $46.5(1)$ & $29.2(1)$ \\
$\mathbf{C}_{\mathbf{2}} \mathbf{H}_{\mathbf{6}}$ & 3.96 & $15.6(3)$ & $36.3(7)$ & 8.33 & $53.5(1)$ & $32.3(1)$ \\
\hline
\end{tabular}

of 73 and $\mathrm{C}_{2} \mathrm{H}_{2} / \mathrm{CH}_{4}$ of 33 (Fig. 2c). The $\mathrm{C}_{2} \mathrm{H}_{4} / \mathrm{CH}_{4}$ and $\mathrm{C}_{2} \mathrm{H}_{2} / \mathrm{CH}_{4}$ selectivity for SBMOF-1 are lower than those of the Fe-MOF-74 (700 and 200, respectively), ${ }^{29}$ because of the presence of open metal sites in the activated framework in the latter case, while SBMOF-1 possesses no open metal sites. However, the $74 \mathrm{C}_{2} \mathrm{H}_{6} / \mathrm{CH}_{4}$ selectivity is more than 3 times higher than for Fe-MOF-74 (20). ${ }^{29}$

SBMOF-2 uptake of $\mathrm{C}_{2} \mathrm{H}_{\mathrm{n}}$ is more than 2 times higher than in the case of SBMOF-1 at $298 \mathrm{~K}$ and 1 bar, and the difference in maximum uptake between methane and $\mathrm{C}_{2} \mathrm{H}_{\mathrm{n}}$ is more prominent than for SBMOF-1. SBMOF-2 adsorbs $17.3 \mathrm{~cm}^{3} / \mathrm{g}$ of methane at $298 \mathrm{~K}$ and $64.7,59.8$ and $62.2 \mathrm{~cm}^{3} / \mathrm{g}$ of acetylene, ethylene and ethane, respectively (Fig. 2b). The maximum uptake of $\mathrm{C}_{2} \mathrm{H}_{\mathrm{n}}$ in SBMOF-2 at 1 bar, $298 \mathrm{~K}$ is lower than for prototypical MOFs such as Fe-MOF-74, or MOF-5 but considerably higher than those of other porous materials extensively studied for hydrocarbon adsorption like ZIF-8 or RPM$3-\mathrm{Zn}{ }^{4,24,25,57} Q_{s t}$ values for $\mathrm{C}_{1}-\mathrm{C}_{2}$ hydrocarbons adsorbed on SBMOF-2 are lower than in the case of the SBMOF-1 material (Table 1). The calculated $\mathrm{C}_{2} / \mathrm{C}_{1}$ selectivity in $\mathrm{SBMOF}-2$ are 26, for $\mathrm{C}_{2} \mathrm{H}_{6} / \mathrm{CH}_{4}, 16$ for $\mathrm{C}_{2} \mathrm{H}_{4} / \mathrm{CH}_{4}$ and 18 for $\mathrm{C}_{2} \mathrm{H}_{2} / \mathrm{CH}_{4}$ (Fig. $2 \mathrm{~d}$ ), also lower than those calculated for SBMOF-1 and FeMOF-74. ${ }^{29}$

As in SBMOF-1 the only presumed interaction between gas molecules and the pore space is $\mathrm{C}^{-\mathrm{H}^{*}} \pi$, it is expected that the $Q_{s t}$ values will decrease with the C-C bond saturation. ${ }^{58,59}$ However, the $Q_{s t}$ values of all three gases are quite similar to each other with the values of 34.8(3), 35.0(5) and 36.3(7) $\mathrm{kJ} / \mathrm{mol}_{\mathrm{GAS}}$ for acetylene, ethyelene and ethane, respectively, suggesting that there is no significant influence of the C-C double or triple bond on the adsorbent-adsorbate interaction. In SBMOF-2 Qst of all $\mathrm{C}_{2} \mathrm{H}_{\mathrm{n}}$ display also similar values, with $30.3(2), 29.2(1)$ and $32.3(1) \mathrm{kJ} / \mathrm{mol}_{\mathrm{GAS}}$ for ethane, ethylene and acetylene, respectively. In both materials however, we can see that ethane interacts with the pore surface with the highest energy of the three, in spite of the full saturation of the C-C bond, normally leading to the lower adsorbent-adsorbate energy. ${ }^{58}$ The $\mathrm{C}_{2} \mathrm{H}_{\mathrm{n}} Q_{s t}$ values for adsorption both on SBMOF-1 and SBMOF-2 suggest that the size of the molecule and the number of the H-pore surface interactions play a more important role on the resultant energy of adsorption than the saturation of the $\mathrm{C}-\mathrm{C}$ bond.

SBMOF-2 was further tested for the adsorption of heavier $\mathrm{C}_{3}-\mathrm{nC}_{4}$ hydrocarbon gases. When looking on the gas adsorption of $\mathrm{C}_{1}-\mathrm{nC}_{4}$ alkanes on SBMOF-2, depicted on Figure 3a, we note that the adsorption follows the general trends observed for porous MOFs such as MOF-5. ${ }^{27,60}$ SBMOF-2 saturates with longer alkanes at lower pressures, and the heavier gas generally displays a lower capacity than the lighter counterpart. $Q_{s t}$ becomes higher with an increase in the chain length due to the enhanced electrostatic and dispersion interactions between the adsorbed gases and the pore surfaces (Fig. 3b). ${ }^{61}$ In mixtures longer chains are preferred over the smaller ones until the point of the maximum selectivity, when the entropic cost of the long chain ordering affects the energy gained from the adsorption. ${ }^{5}$

The separation performance of industrial fixed bed adsorbents is dictated by a combination of adsorption selectivity and uptake capacity. In order to demonstrate the potential of SBMOF-1 and SBMOF-2 for separation of hydrocarbon mixtures, we performed transient breakthrough simulations. The results for separation of equimolar 4-component $\mathrm{CH}_{4} / \mathrm{C}_{2} \mathrm{H}_{2} / \mathrm{C}_{2} \mathrm{H}_{4} / \mathrm{C}_{2} \mathrm{H}_{6}$ mixture using SBMOF-1 at $298 \mathrm{~K}$, with partial pressures of $25 \mathrm{kPa}$ each are presented on Figure $5 \mathrm{a}$. Since the $\mathrm{C}_{2} \mathrm{H}_{6} / \mathrm{CH}_{4}$, and $\mathrm{C}_{2} \mathrm{H}_{4} / \mathrm{CH}_{4}$ selectivities are practically the same (Fig. 2b), the breakthroughs of $\mathrm{C}_{2} \mathrm{H}_{4}$, and $\mathrm{C}_{2} \mathrm{H}_{6}$ occur at practically the same time. The sequence of breakthroughs in Figure $5 \mathrm{a}$ indicates that SBMOF-1 has the potential of separating methane from $\mathrm{C}_{2}$ hydrocarbon mixtures. Figure $5 \mathrm{~b}$ depicts the corresponding transient breakthrough simulations for separation of $\mathrm{C}_{1} / \mathrm{C}_{2}$ mixtures using SBMOF-2. SBMOF-2 has significantly higher uptake capacities for hydrocarbons as compared to SBMOF-1 (Figures 2a, 2b); consequently the breakthrough times with SBMOF-2 are significantly higher than the corresponding breakthrough times with SBMOF-1. Longer breakthrough times are desirable because this implies longer cycle times before the bed has to be regenerated. We therefore conclude that SBMOF-2 has superior separation performance for $\mathrm{C}_{1} / \mathrm{C}_{2}$ separations as compared to SBMOF-1. Finally, we studied how SBMOF-2 performs in separating $\mathrm{C}_{1}-\mathrm{nC}_{4} 7$ components mixtures. He et al. previously demonstrated the capability of M-MOF-74 for adsorptive "fractionation" of a $\mathrm{C}_{1} / \mathrm{C}_{2} / \mathrm{C}_{3}$ hydrocarbon mixture. ${ }^{62}$ We now established a similar fractionation capability of SBMOF-2. The breakthrough simulation data in Figure $5 \mathrm{c}$ demonstrate that SBMOF-2 has the ability to separate a 7-component $\mathrm{CH}_{4} / \mathrm{C}_{2} \mathrm{H}_{2} / \mathrm{C}_{2} \mathrm{H}_{4} / \mathrm{C}_{2} \mathrm{H}_{6} / \mathrm{C}_{3} \mathrm{H}_{6} / \mathrm{C}_{3} \mathrm{H}_{8} / \mathrm{C}_{4} \mathrm{H}_{10}$ mixture into four different fractions, with increasing carbon numbers. The separation potential of SBMOF-2 is best appreciated by viewing the video animation that shows the transient traversal of gas phase concentrations of each of the seven component along the length of the fixed bed adsorber.

To supplement the simulated breakthrough we carried out the experimental breakthrough of equimolar 4-component $\mathrm{CH}_{4} / \mathrm{C}_{2} \mathrm{H}_{2} / \mathrm{C}_{2} \mathrm{H}_{4} / \mathrm{C}_{2} \mathrm{H}_{6}$ mixture using SBMOF-1 at $296 \mathrm{~K}$. As 
(a)

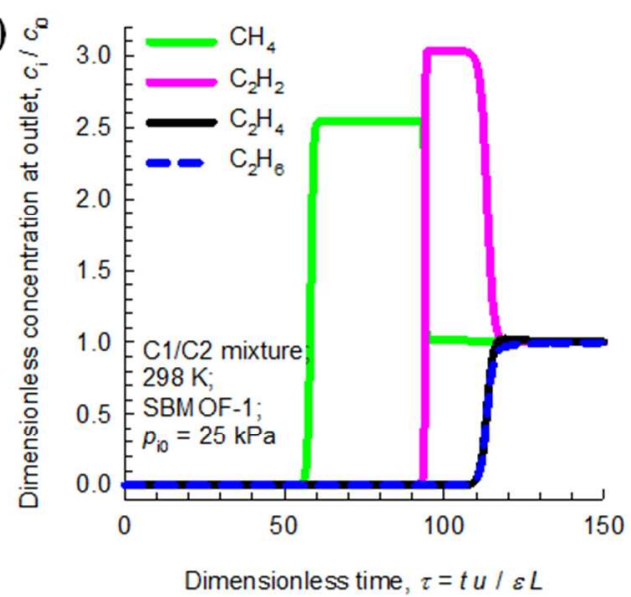

(b)

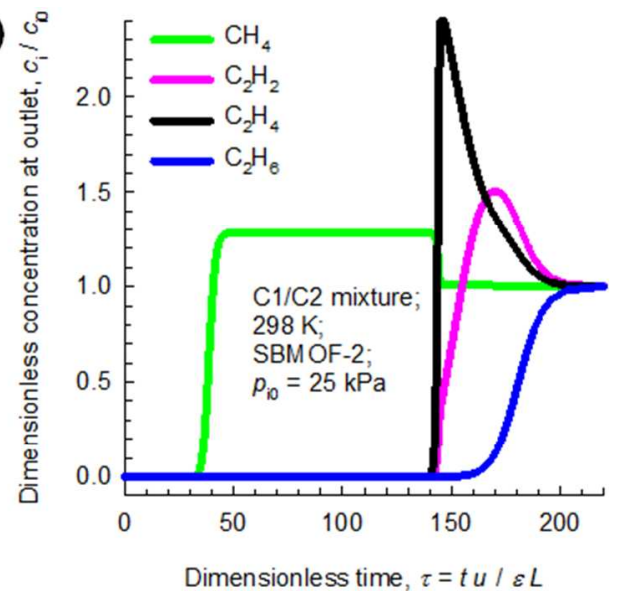

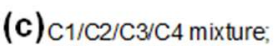
298 K: SBMOF-2: $\quad-\mathrm{CH}_{4}$ 298 $p_{i 0}=25 \mathrm{kPa}$

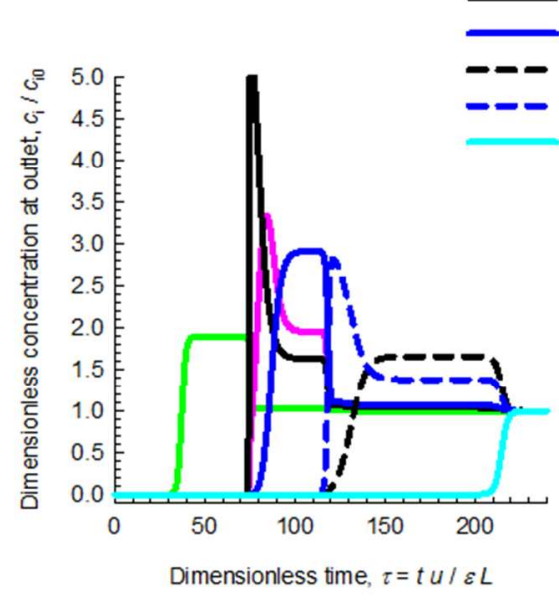

Figure 5. Transient breakthrough simulations for: (a) separation of equimolar 4-component $\mathrm{CH}_{4} / \mathrm{C}_{2} \mathrm{H}_{2} / \mathrm{C}_{2} \mathrm{H}_{4} / \mathrm{C}_{2} \mathrm{H}_{6}$ mixture using SBMOF-1 at $298 \mathrm{~K}$, with partial pressures of $25 \mathrm{kPa}$ each; (b) separation of equimolar 4-component $\mathrm{CH}_{4} / \mathrm{C}_{2} \mathrm{H}_{2} / \mathrm{C}_{2} \mathrm{H}_{4} / \mathrm{C}_{2} \mathrm{H}_{6}$ mixture using SBMOF-2 at $298 \mathrm{~K}$, with partial pressures of $25 \mathrm{kPa}$ each; (c) separation of equimolar 7-component $\mathrm{CH}_{4} / \mathrm{C}_{2} \mathrm{H}_{2} / \mathrm{C}_{2} \mathrm{H}_{4} / \mathrm{C}_{2} \mathrm{H}_{6} / \mathrm{C}_{3} \mathrm{H}_{6} / \mathrm{C}_{3} \mathrm{H}_{8} / \mathrm{C}_{4} \mathrm{H}_{10}$ mixture using SBMOF-2 at $298 \mathrm{~K}$, with partial pressures of $25 \mathrm{kPa}$ each.

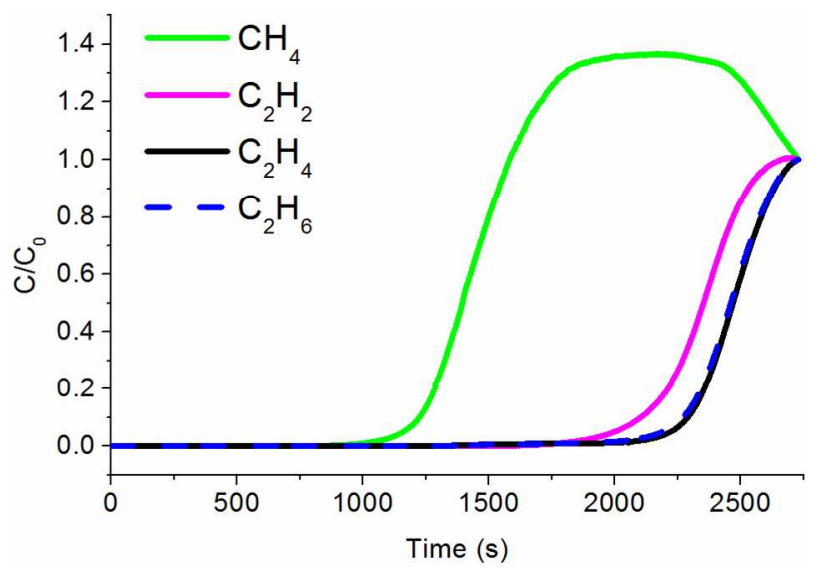

Figure 6. Experimental column breakthrough curve for a gas mixture of $\mathrm{CH}_{4} / \mathrm{C}_{2} \mathrm{H}_{2} / \mathrm{C}_{2} \mathrm{H}_{4} / \mathrm{C}_{2} \mathrm{H}_{6}(25: 25: 25: 25$, v/v, $296 \mathrm{~K}, 1$ bar $)$ in a fixed bed packed with SBMOF-1.

shown on the Figure 6, the experimental results are in excellent agreement with the simulations, showing the same gas separation sequence.

Further, we used single crystal diffraction technique to determine the positions of adsorbed molecules in $\mathrm{C}_{2} \mathrm{H}_{\mathrm{n}}$ :SBMOF1 and SBMOF-2 gas adducts. Refined occupancies of the adsorbed gases are in the average within less than $10 \%$ from the values obtained with gas-adsorption experiments, confirming the validity of the technique (Table S5). Main presumed adsorbate-host interactions in SBMOF-1 and SBMOF-2 are the $\mathrm{C}-\mathrm{H} \cdots \pi$ and $\mathrm{C}-\mathrm{H}^{\cdots} \mathrm{O}$, with the latter appearing only in the channels of the type II in SBMOF-2. Such interactions play a significant role in the molecular crystals packing, protein folding and molecular recognition. ${ }^{59,61,63}$

Analysis of the structural data of SBMOF-1: $\mathrm{C}_{2} \mathrm{H}_{\mathrm{n}}$ collected at $100 \mathrm{~K}$ revealed that upon the loading with $\mathrm{C}_{2} \mathrm{H}_{\mathrm{n}}$, sdb linkers rotated back to a parallel configuration observed in the assynthesized material. Adsorbates locate on the inversion center at the center of the pore. In each structure half of the $\mathrm{C}_{2} \mathrm{H}_{n}$ molecule is within the asymmetric unit and the second half is generated by the symmetry operation. Distances between hydrogen atoms of the $\mathrm{C}_{2} \mathrm{H}_{n}$ molecules and neighboring phenyl ring centroids are within $3.07(4)-3.36(4) \AA$ (Fig. 7). The distance between adsorbate molecules along the channel is equivalent to a lattice parameter $b: 5.556(1) \AA$. The parallel orientation of the linkers provides the optimal geometry for the hydrocarbon molecules, forming cages of four phenyl rings. The ethylene molecule is oriented so that each of the $\mathrm{H}$ atoms is pointing towards the closest phenyl ring with the average distance of 3.15(9) $\AA$. Ethane and acetylene gases locate in a similar fashion, with the average $\mathrm{C}-\mathrm{H}^{\cdots}{ }^{*} \pi$ distances of 3.4(1) and 3.23(8) A, respectively. Acetylene and ethylene molecules display a two-fold disorder while ethane shows no spatial disorder.

In SBMOF-2 gas adsorption sites differ between channels of type I and II. In the type I channels, the only presumed interactions are between hydrogen atoms of adsorbates and $\pi$ clouds of organic linkers. The adsorbates locate within less than $4 \AA$ distance to two or four phenyl rings at a time. The shortest C$\mathrm{H}^{*} \pi$ lengths, measured as a distance between the $\mathrm{H}$ atom and the phenyl centroid, are 3.11(2), 3.09(2) and 3.10(2) $\AA$ for acetylene, ethylene and ethane, respectively (Fig. 7). All three adsorbates can be located unambiguously from the electron density maps and all three, except acetylene in channels of 
(a)
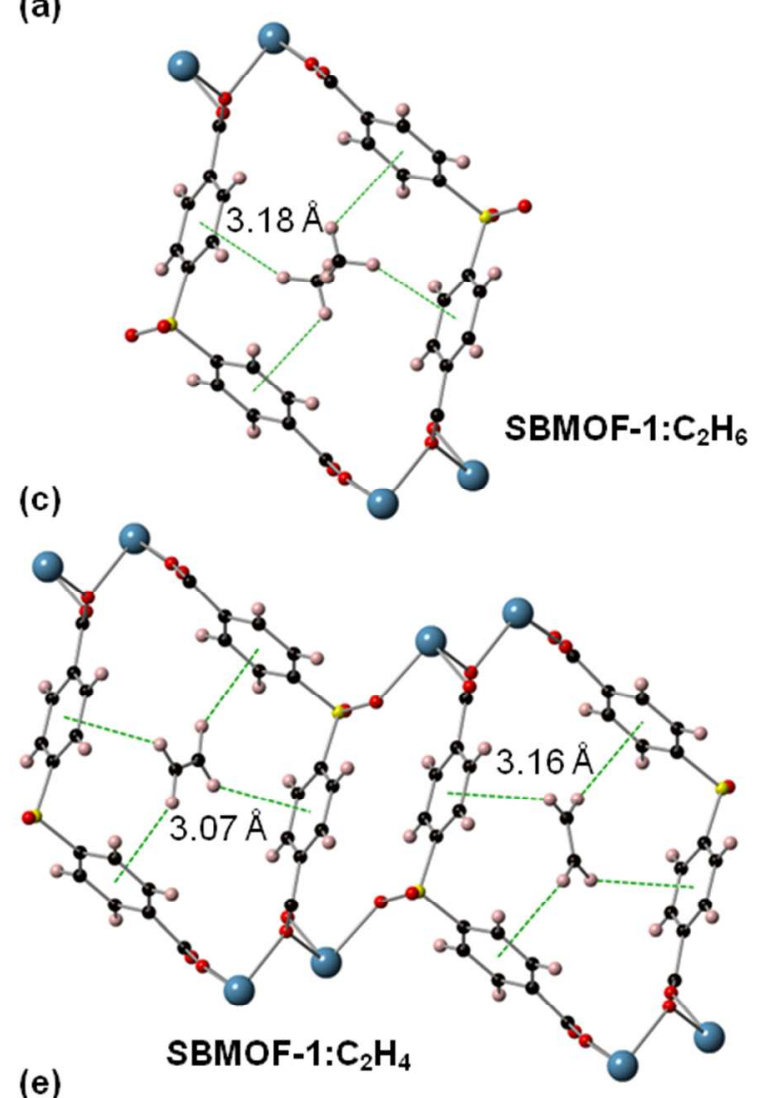

(e)

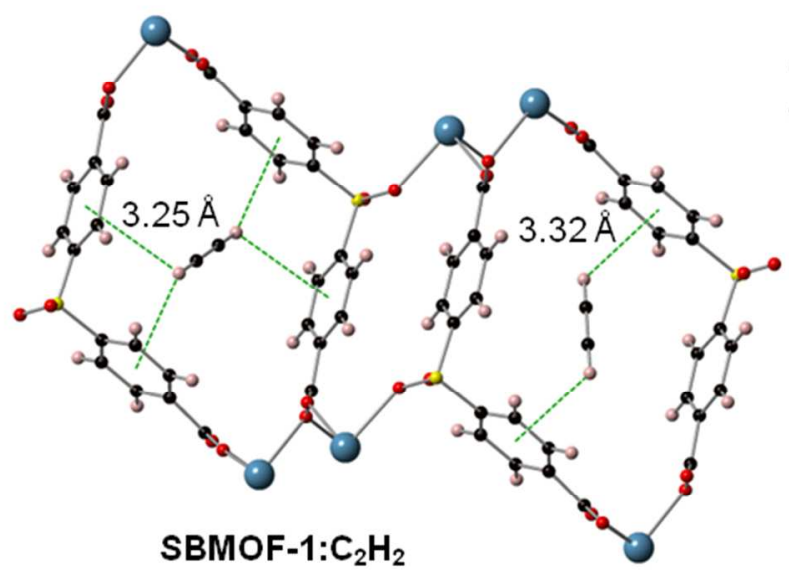

(b)

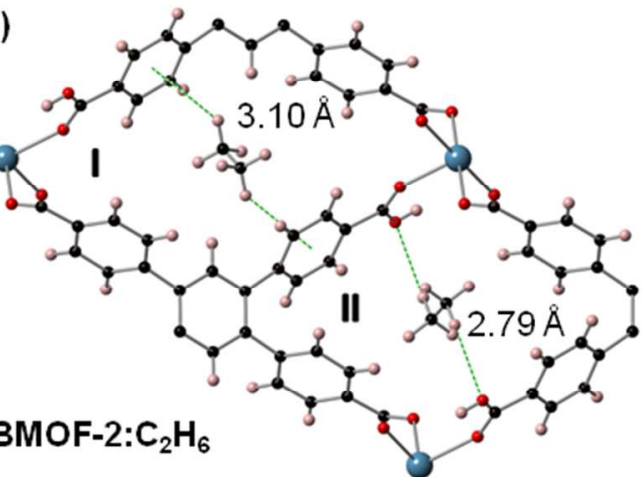

(d)

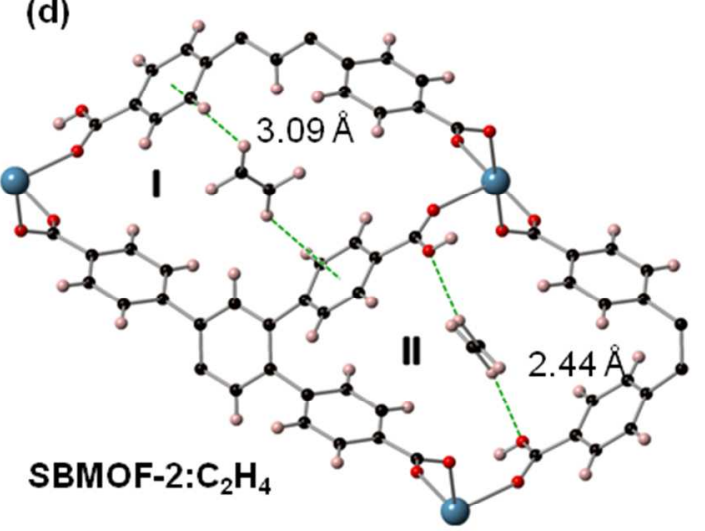

(f)
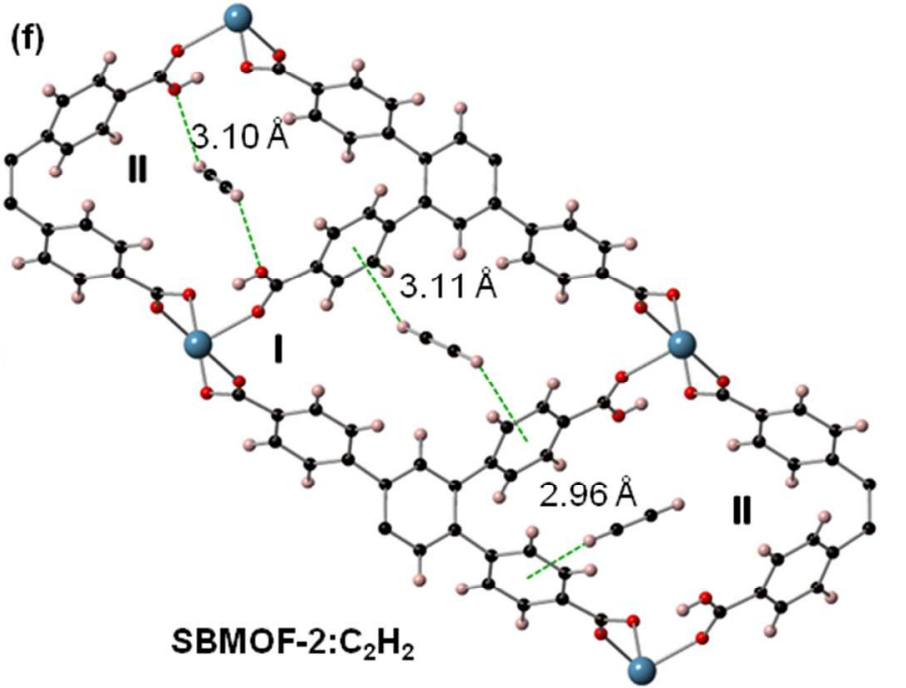

Figure 7. $\mathrm{C}_{2}$ hydrocarbon adsorption sites in SBMOF-1 and SBMOF-2, shortest gas-sorption site distances are shown. In cases where gas displays disorder, second orientation is shown in a consecutive pore; ethane adsorption sites in (a) SBMOF-1 and (b) SBMOF-2; ethylene adsorption sites in (c) SBMOF-1 and (d) SBMOF-2; acetylene adsorption sites in (e) SBMOF-1 and (f) SBMOF-2.

type II, show no spatial disorder. In the type II channels pore surface is decorated with multiple oxygen atoms including the -OH groups within the $4 \AA$ from the center of the pore, and provides strong adsorption sites for the adsorbates through the presumed $\mathrm{C}-\mathrm{H}^{\cdots} \mathrm{O}$ interaction (Fig. 7). The shortest $\mathrm{C}-\mathrm{H}^{\cdots} \mathrm{O}$ distances are: 3.10(2), 2.44(2) and 2.79(2) $\AA$ for acetylene, ethylene and ethane, respectively.

In situ PXRD diffraction patterns of SBMOF-1 and SBMOF-2 confirm the adsorption mechanisms determined from single crystal diffraction. Upon gas loading, low angle peaks decrease with respect to higher angle reflections, consistent with the gas molecules occupying the pore space (Fig. 8). Further,
SBMOF-2 shows an increasing lattice change with the size of adsorbates as evident from the shifting of peaks' positions in the PXRD patterns (Fig. 8b, Fig. S17 - S26). The lattice dimension $a$ increases and the $\alpha$ angle decreases from 5.1011(3) $\AA$ and $83.132(5)^{\circ}$ in the activated sample to 5.2195(2) $\AA$ and $82.533(1)^{\circ}$ in the SBMOF-2: $\mathrm{C}_{2} \mathrm{H}_{6}$, as determined from single crystal data and consistent with PXRD observations (Figs. S21 -25 ). The $a$ parameter is equivalent to the distance between adsorbed gas molecules along the pore. In situ PXRD data collected at $298 \mathrm{~K}$ from $\mathrm{C}_{3}-\mathrm{C}_{4}$ gas-loaded SBMOF-2 show further increasing change between activated and gas-loaded material with increasing length of hydrocarbon chain, 

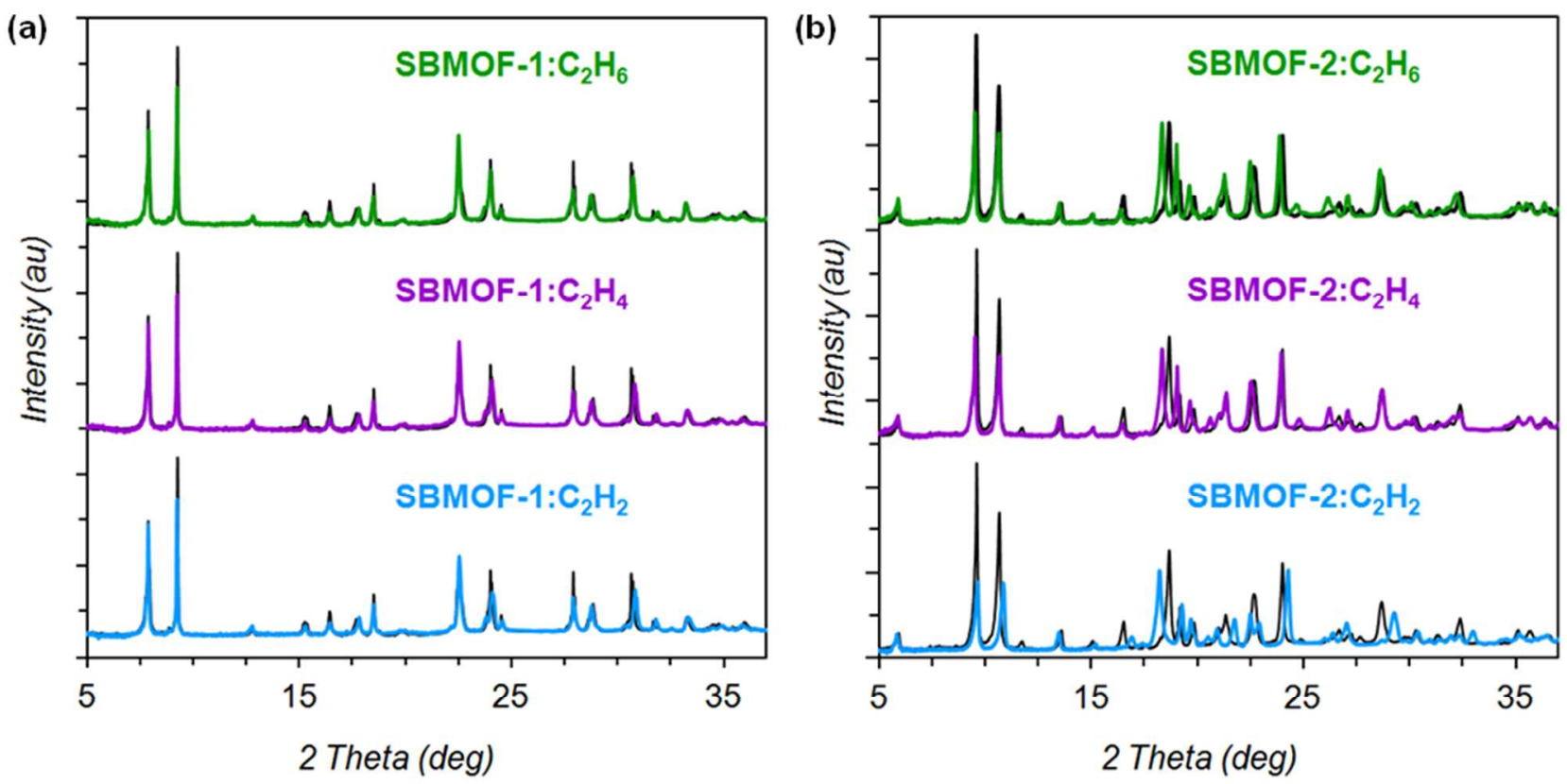

Figure 8. In situ PXRD collected at $1 \mathrm{~atm}$ pressure of $\mathrm{C}_{2}$ hydrocarbons for (a) SBMOF-1 and (b) SBMOF-2. Black patterns represent activated samples.

suggesting that SBMOF-2 framework is flexible and can accommodate larger molecules (Figs. S29 - S32).

\section{CONCLUSIONS}

We characterized adsorption mechanisms of ethane, ethylene and acetylene in two microporous Ca-based metal organic frameworks, SBMOF-1 and SBMOF-2. Both materials are selective towards $\mathrm{C}_{2} \mathrm{H}_{\mathrm{n}}$ hydrocarbons over methane with the maximum $\mathrm{C}_{2} / \mathrm{C}_{1}$ selectivity of 74 for $\mathrm{C}_{2} \mathrm{H}_{6} / \mathrm{CH}_{4}$ in SBMOF-1. The breakthrough simulation data confirmed that both SBMOF-1 and SBMOF-2 can separate $\mathrm{C}_{1} / \mathrm{C}_{2}$ mixtures. SBMOF-2 also has the ability to separate a 7component $\mathrm{CH}_{4} / \mathrm{C}_{2} \mathrm{H}_{2} / \mathrm{C}_{2} \mathrm{H}_{4} / \mathrm{C}_{2} \mathrm{H}_{6} / \mathrm{C}_{3} \mathrm{H}_{6} / \mathrm{C}_{3} \mathrm{H}_{8} / \mathrm{C}_{4} \mathrm{H}_{10}$ mixture into four different fractions, with increasing carbon numbers. Crystal structure of the gas-loaded SBMOF-1 shows that the framework behaves like a trap towards the $\mathrm{C}_{2}$ hydrocarbons. The pore geometry in SBMOF-1 is optimal for the small $\mathrm{C}_{2} \mathrm{H}_{\mathrm{n}}$ molecules, as each of the pore segments is built with four phenyl rings, providing strong adsorption sites through $\mathrm{C}-\mathrm{H}^{\cdots} \pi$ interactions. SBMOF-2 contains two types of channels, in the first type only phenyl rings are accessible as adsorption sites for hydrocarbon molecules, while the second type contains multiple $\mathrm{O}$ atoms in the close proximity to the center of the pore. The adsorbate-adsorbent interaction in SBMOF-2 appears to be similar to the SBMOF-1 case, except in those channels where additional polarizing - $\mathrm{OH}$ groups and oxygen atoms serve as strong adsorption sites for $\mathrm{C}_{2} \mathrm{H}_{\mathrm{n}}$, through the C$\mathrm{H}^{\cdots} \mathrm{O}$ interaction. Those single crystal data are confirmed by the experimental gas adsorption and the XRD-DSC studies. In situ XRD-DSC results further suggest that SBMOF-2 displays some network flexibility, which allows accommodation of all the $\mathrm{C}_{1}-\mathrm{nC}_{4}$ hydrocarbon gases inside the pore space.

\section{ASSOCIATED CONTENT}

Supporting Information. Figures S1-S32, Tables S1-S5 and crystallographic data (CIF). This material is available free of charge via the Internet at http://pubs.acs.org.

\section{AUTHOR INFORMATION}

\section{Corresponding Authors}

*anna.plonka@yu.edu,

*jingli@rutgers.edu,

*r.krishna@,contact.uva.nl

\section{Present Addresses}

$†$ Physics Department, Yeshiva University, New York Office: 342, Building 555, Brookhaven National Laboratory, Upton, NY 11973

†F Northwest National Laboratory, Richland, Washington 99352, USA

\section{Author Contributions}

The manuscript was written through contributions of all authors.

\section{ACKNOWLEDGMENT}

Synthetic strategies for development of SBMOF-2, SCXRD and DSC-XRD characterization work and analysis of synchrotron data at Stony Brook by A.M.P., X.C., J.B.P. and W.R.W was supported by the National Science Foundation grant DMR1231586. Structures of SBMOF-1: $\mathrm{C}_{2} \mathrm{H}_{2}$, SBMOF-1: $\mathrm{C}_{2} \mathrm{H}_{4}$, SBMOF-2: $\mathrm{C}_{2} \mathrm{H}_{2}$ and SBMOF-2: $\mathrm{C}_{2} \mathrm{H}_{4}$ were determined using the Stony Brook University single-crystal diffractometer, obtained through the support of the NSF (grant number CHE-0840483). Structures of SBMOF-1: $\mathrm{C}_{2} \mathrm{H}_{6}$ and SBMOF-2: $\mathrm{C}_{2} \mathrm{H}_{6}$ were determined in ChemMatCars (Sector 15), Advanced Photon Source 
(APS), principally supported by the National Science Foundation/Department of Energy (NSF/CHE-0822838). Use of APS was supported by the U.S. Department of Energy, Office of Science, Office of Basic Energy Sciences under contract no. DEAC02-06CH11357. The RU team acknowledges the partial support for the gas adsorption work and IAST calculations by the U.S. Department of Energy, Office of Science, Office of Basic Energy Sciences through Grant DE-FG02-08ER46491. Y. H. thanks KAUST for the Competitive Research Funds under Awards No. URF/1/1672-01-01.

\section{REFERENCES}

(1) Cao, C.; Chung, T.-S.; Liu, Y.; Wang, R.; Pramoda, K. Chemical Cross-Linking Modification of 6FDA-2, 6-DAT Hollow Fiber Membranes for Natural Gas Separation. J. Membr. Sci. 2003, 216, 257-268.

(2) Duan, X; Zhang, Q.; Cai, J.; Cui, Y.; Wu, C.; Yang. Y.; Qian, G. A New Microporous Metal-Organic Framework with Potential for Highly Selective Separation Methane from Acetylene, Ethylene and Ethane at Room Temperature. Microporous Mesoporous Mater. 2014, 190, 32-37.

(3) Magnowski, N.; Avila, A.; Lin, C.; Shi, M.; Kuznicki, S. Extraction of Ethane from Natural Gas by Adsorption on Modified ETS-10. Chem. Eng. Sci. 2011, 66, 1697-1701.

(4) Banerjee, D.; Liu, J.; Thallapally, P. K. Separation of $\mathrm{C}_{2}$ Hydrocarbons by Porous Materials: Metal Organic Frameworks as Platform. Comments Inorg. Chem. 2015, 35, 18-38.

(5) Herm, Z. R.; Bloch, E. D.; Long, J. R. Hydrocarbon Separations in Metal-Organic Frameworks. Chem. Mater. 2013, 26, 323-338.

(6) Jarvelin, H.; Fair, J. R. Adsorptive Separation of Propylene-Propane Mixtures. Ind. Eng. Chem. Res. 1993, 32, 2201-2207.

(7) Matsufuji, T.; Nishiyama, N.; Matsukata, M.; Ueyama, K. Separation of Butane and Xylene Isomers with MFI-Type Zeolitic Membrane Synthesized by a Vapor-Phase Transport Method. J. Membr. Sci. 2000, 178, 25-34.

(8) Li, B.; Zhang, Y.; Krishna, R.; Yao, K.; Han, Y.; Wu, Z.; Ma, D.; Shi, Z.; Pham, T.; Space, B.; Liu, J.; Thallapally, P. K.; Liu, J.; Chrzanowski, M.; Ma, S. Introduction of $\pi$ Complexation into Porous Aromatic Framework for Highly Selective Adsorption of Ethylene over Ethane. J. Am. Chem. Soc. 2014, 136, 8654-8660.

(9) Getman, R. B.; Bae, Y.-S.; Wilmer, C. E.; Snurr, R. Q. Review and Analysis of Molecular Simulations of Methane, Hydrogen, and Acetylene Storage in Metal-Organic Frameworks. Chem. Rev. 2011, 112, 703-723.

(10) Suh, M. P.; Park, H. J.; Prasad, T. K.; Lim, D.-W Hydrogen Storage in Metal-Organic Frameworks. Chem. Rev. 2011, 112, 782-835.

(11) Sumida, K.; Rogow, D. L.; Mason J. A.; McDonald, T. M.; Bloch, E. D.; Herm, Z. R.; Bae, T.-H.; Long, J. R. Carbon Dioxide Capture in Metal-Organic Frameworks. Chem. Rev. 2011, 112, 724-781.

(12) Wu, H.; Gong, Q.; Olson, D. H.; Li, J. Commensurate Adsorption of Hydrocarbons and Alcohols in Microporous Metal Organic Frameworks. Chem. Rev. 2012, 112, 836-868.

(13) Li, J.-R.; Sculley, J.; Zhou, H.-C. Metal-Organic Frameworks for Separations. Chem. Rev. 2011, 112, 869-932.

(14) Stock, N.; Biswas, S. Synthesis of Metal-Organic Frameworks (MOFs): Routes to Various MOF Topologies, Morphologies, and Composites. Chem. Rev. 2011, 112, 933-969.

(15) Cohen, S. M. Postsynthetic Methods for the Functionalization of Metal-Organic Frameworks. Chem. Rev. 2011, 112, 970-1000.
(16) Kreno, L. E.; Leong, L.; Farha, O. K.; Allendorf, M.; Van Duyne, R. P.; Hupp, J. T.; Metal-Organic Framework Materials as Chemical Sensors. Chem. Rev. 2011, 112, 11051125.

(17) Qiu, S.; Xue, M.; Zhu, G. Metal-Organic Framework Membranes: from Synthesis to Separation Application. Chem. Soc. Rev. 2014, 43, 6116-6140.

(18) Canivet, J.; Fateeva, A.; Guo, Y.; Coasne, B. Farrusseng, D. Water Adsorption in MOFs: Fundamentals and Applications. Chem. Soc. Rev. 2014, 43, 5594-5617.

(19) Zhang, T.; Lin, W. Metal-Organic Frameworks for Artificial Photosynthesis and Photocatalysis. Chem. Soc. Rev. 2014, 43, 5982-5993.

(20) Ramaswamy, P.; Wong, N. E.; Shimizu, G. K. H. MOFs as Proton Conductors - Challenges and Opportunities. Chem. Soc. Rev. 2014, 43, 5913-5932.

(21) He, Y.; Zhou, W.; Qian, G.; Chen, B. Methane Storage in Metal-Organic Frameworks. Chem. Soc. Rev. 2014, 43, 56575678.

(22) Van de Voorde, B.; Bueken, B.; Denayer, J.; De Vos, D. Adsorptive Separation on Metal-Organic Frameworks in the Liquid Phase. Chem. Soc. Rev. 2014, 43, 5766-5788.

(23) Hu, Z.; Deibert, B. J.; Li, J. Luminescent Metal-Organic Frameworks for Chemical Sensing and Explosive Detection. Chem. Soc. Rev. 2014, 43, 5815-5840.

(24) Nijem, N.; Wu, H.; Canepa, P.; Marti, A.; Balkus Jr, K. J.; Thonhauser, T.; Li, J.; Chabal, Y. J. Tuning the Gate Opening Pressure of Metal-Organic Frameworks (MOFs) for the Selective Separation of Hydrocarbons. J. Am. Chem. Soc. 2012, 134, 15201-15204.

(25) Gücüyener, C.; van den Bergh, J.; Gascon, J.; Kapteijn, F. Ethane/Ethene Separation Turned on Its Head: Selective Ethane Adsorption on the Metal-Organic Framework ZIF-7 through a Gate-Opening Mechanism. J. Am. Chem. Soc. 2010, 132, 1770417706.

(26) Farrusseng, D.; Daniel, C.; Gaudillere, C.; Ravon, U.; Schuurman, Y.; Mirodatos, C.; Dubbeldam, D.; Frost, H.; Snurr, R. Q. Heats of Adsorption for Seven Gases in Three MetalOrganic Frameworks: Systematic Comparison of Experiment and Simulation. Langmuir 2009, 25, 7383-7388.

(27) Jiang, J.; Sandler, S. I. Monte Carlo Simulation for the Adsorption and Separation of Linear and Branched Alkanes in IRMOF-1. Langmuir 2006, 22, 5702-5707.

(28) Munch, A. S.; Mertens, F. O. R. L. HKUST-1 as an Open Metal Site Gas Chromatographic Stationary Phase-Capillary Preparation, Separation of Small Hydrocarbons and Electron Donating Compounds, Determination of Thermodynamic Data. $J$. Mater. Chem. 2012, 22, 10228-10234.

(29) Bloch, E. D.; Queen, W. L.; Krishna, R.; Zadrozny, J. M.; Brown, C. M.; Long, J. R.; Hydrocarbon Separations in a Metal-Organic Framework with Open Iron(II) Coordination Sites. Science 2012, 335, 1606-1610.

(30) Matsuda, R.; Kitaura, R.; Kitagawa, S.; Kubota, Y.; Belosludov, R. V.; Kobayashi, T. C.; Sakamoto, H.; Chiba, T.; Masaki, T.; Kawazoe, Y. Highly Controlled Acetylene Accommodation in a Metal-Organic Microporous Material. Nature 2005, 436, 238-241.

(31) Alaerts, L.; Kirschhock, C. E. A.; Maes, M.; van der Veen, M. A.; Finsy, V.; Depla, A.; Martens, J. A.; Baron, G. V.; Jacobs, P. A.; Denayer, J. F. M.; De Vos, D. E. Selective Adsorption and Separation of Xylene Isomers and Ethylbenzene with the Microporous Vanadium(IV) Terephthalate MIL-47. Angew. Chem. Int. Ed. 2007, 46, 4293-4297.

(32) Carrington, E. J.; Vitorica-Yrezabal, I. J.; Brammer, L. Crystallographic Studies of Gas Sorption in Metal-Organic Frameworks. Acta Crystallogr. Sect. B 2014, 70, 404-422. 
(33) Samsonenko, D. G.; Kim, H.; Sun, Y.; Kim, G.-H.; Lee, H.-S.; Kim, K. Microporous Magnesium and Manganese Formates for Acetylene Storage and Separation. Chem. Asian J. 2007, 2, 484-488.

(34) Kim, H.; Samsonenko, D. G.; Das, S.; Kim, G.-H., Lee, H.-S.; Dybtsev, D. N.; Berdonosova, E. A.; Kim, K. Methane Sorption and Structural Characterization of the Sorption Sites in $\mathrm{Zn}_{2}$ (bdc) ${ }_{2}$ (dabco) by Single Crystal X-ray Crystallography. Chem. Asian J. 2009, 4, 886-891.

(35) Miller, S. R.; Wright, P. A.; Devic. T.; Serre, C.; Ferey, G.; Llewellyn, P. L.; Denoyel, R.; Gaberova, L.; Filinchuk, Y. Single Crystal X-ray Diffraction Studies of Carbon Dioxide and Fuel-Related Gases Adsorbed on the Small Pore Scandium Terephthalate Metal Organic Framework, $\mathrm{Sc}_{2}\left(\mathrm{O}_{2} \mathrm{CC}_{6} \mathrm{H}_{4} \mathrm{CO}_{2}\right)_{3}$. Langmuir 2009, 25, 3618-3626.

(36) Zhang, J.-P.; Chen, X.-M. Optimized Acetylene/Carbon Dioxide Sorption in a Dynamic Porous Crystal. J. Am. Chem. Soc.2009, 131, 5516-5521.

(37) Noro, S.-i.; Mizutani, J.; Hijikata, R.; Matsuda, R.; Sato, H.; Kitagawa, S.; Sugimoto, K.; Inubushi, Y.; Kubo, K.; Nakamura, T. Porous Coordination Polymers with Ubiquitous and Biocompatible Metals and a Neutral Bridging Ligand. Nat. Commun. 2015, 6, 5851.

(38) Mallick, A.; Saha, S.; Pachfule, P.; Roy, S.; Banerjee, R. Selective $\mathrm{CO}_{2}$ and $\mathrm{H}_{2}$ adsorption in a Chiral Magnesium-based Metal Organic Framework (Mg-MOF) with Open Metal Sites. $J$ Mater. Chem. 2010, 20, 9073-80.

(39) Britt, D.; Furukawa, H.; Wang, B.; Glover, T. G.; Yaghi, O. M. Highly Efficient Separation of Carbon Dioxide by a Metal-Organic Framework Replete with Open Metal sites. Proc. Nat. Acad. Sci. 2009, 106, 20637-40.

(40) Banerjee, D.; Zhang, Z.; Plonka, A. M.; Li, J.; Parise, J. B. A Calcium Coordination Framework Having Permanent Porosity and High $\mathrm{CO}_{2} / \mathrm{N}_{2}$ Selectivity. Cryst. Growth Desi. 2012, 12, 2162-2165.

(41) Plonka, A. M.; Banerjee, D.; Parise, J. B. Effect of Ligand Structural Isomerism in Formation of Calcium Coordination Networks. Cryst. Growth Des. 2012, 12, 2460-2467.

(42) Chen, X., Plonka, A. M., Banerjee, D.; Parise, J. B. Synthesis, Structures and Photoluminescence Properties of a Series of Alkaline Earth Metal-Based Coordination Networks Synthesized Using Thiophene-Based Linkers. Crys. Growth Des. 2012, 13, 326-332.

(43) Chen, X.; Plonka, A. M.; Banerjee, D.; Krishna, R.; Schaef, H. T.; Ghose, S.; Thallapally, P. K.; Parise, J. B. Direct Observation of $\mathrm{Xe}$ and $\mathrm{Kr}$ Adsorption in a Xe-selective Microporous Metal Organic Framework. J. Am. Chem. Soc. 2015, 137, 7007-7010.

(44) Myers, A. L.; Prausnitz, J. M. Thermodynamics of Mixed-Gas Adsorption. AIChE J. 1965, 11, 121-127.

(45) Krishna, R. Methodologies for Evaluation of MetalOrganic Frameworks in Separation Applications. RSC Adv. 2015 , 5, 52269-52295.

(46) Spek, A. Single-Crystal Structure Validation with the Program PLATON. J. Appl. Crystallogr. 2003, 36, 7-13.

(47) Plonka, A. M.; Banerjee, D.; Woerner, W. R.; Zhang, Z.; Nijem, N.; Chabal, Y. J.; Li, J.; Parise, J. B. Mechanism of Carbon Dioxide Adsorption in a Highly Selective Coordination
Network Supported by Direct Structural Evidence. Angew. Chem. Int. Ed. 2013, 52, 1692-1695.

(48) Cessford, N. F.; Seaton, N. A.; Düren, T. Evaluation of Ideal Adsorbed Solution Theory as a Tool for the Design of Metal-Organic Framework Materials. Ind. Eng. Chem. Res. 2012, 51, 4911-4921.

(49) Zhao, Y.; Liu, X.; Han, Y. Microporous Carbonaceous Adsorbents for $\mathrm{CO}_{2}$ Separation via Selective Sdsorption. RSC Adv. 2015, 5, 30310-30.

(50) Oxford Diffraction. CrysAlis Pro and CrysAlis RED. Oxford Diffraction Ltd, Abingdon, England, 2007.

(51) Bruker AXS Inc. APEX II Software Package. Bruker Analytical X-ray System Inc., Madison, WI, USA, 2005.

(52) Sheldrick, G. A Short History of SHELX. Acta Crystallogr. Sect. A 2008, 64, 112-122.

(53) Sheldrick, G. SHELXTL, Structure Determination Software Programs. Bruker Analytical X-ray System Inc., Madison, WI, USA, 1997.

(54) Farrugia, L. WinGX and ORTEP for Windows: an Update. J. Appl. Cryst. 2012, 45, 849-854.

(55) Plonka, A. M.; Banerjee, D.; Woerner, W. R.; Zhang, Z.; Li, J.; Parise, J. B. Effect of Ligand Geometry on Selective Gas-Adsorption: the Case of a Microporous Cadmium Metal Organic Framework with a V-shaped Linker. Chem. Commun. 2013, 49, 7055-7057.

(56) Woerner, W. R.; Plonka, A. M.; Chen, X.; Banerjee, D.; Thallapally, P. K.; Parise, J. B. Simultaneous in situ X-ray Diffraction and Calorimetric Studies as a Tool to Evaluate Gas Adsorption in Microporous Materials J. Phys. Chem. C DOI: 10.1021/acs.jpcc.5b10159

(57) Fairen-Jimenez, D.; Galvelis, R.; Torrisi, A.; Gellan, A. D.; Wharmby, M. T.; Mellot-Draznieks, C.; Duren, T. Flexibility and Swing Effect on the Adsorption of Energy-Related Gases on ZIF-8: Combined Experimental and Simulation Study. Dalton Trans. 2012, 41, 10752-10762.

(58) Tsuzuki, S.; Fujii, A. Nature and Physical Origin of $\mathrm{CH} / \pi$ Interaction: Significant Difference from Conventional Hydrogen Bonds. Phys. Chem. Chem. Phys. 2008, 10, 2584-2594.

(59) Melandri, S. "Union is strength": How Weak Hydrogen Bonds Become Stronger. Phys. Chem. Chem. Phys. 2011, 13, 13901-13911.

(60) Düren, T.; Snurr, R. Q. Assessment of Isoreticular Metal-Organic Frameworks for Adsorption Separations: A Molecular Simulation Study of Methane/n-Butane Mixtures. $J$. Phys. Chem. B 2004, 108, 15703-15708.

(61) Nishio, M.; Umezawa, Y.; Honda, K.; Tsuboyama, S.; Suezawa, H. $\mathrm{CH} / \pi$ Hydrogen Bonds in Organic and Organometallic Chemistry. CrystEngComm 2009, 11, 1757-1788.

(62) He, Y.; Krishna, R.; Chen, B. Metal-Organic Frameworks with Potential for Energy-Efficient Adsorptive Separation of Light Hydrocarbons. Energy Environ. Sci. 2012, 5, 9107-9120.

(63) Tsuzuki, S.; Fujii, A. Nature and Physical Origin of $\mathrm{CH} / \pi$ Interaction: Significant Difference from Conventional Hydrogen Bonds. Phys. Chem. Chem. Phys. 2008, 10, 2584-2594.

(64) Momma, K.; Izumi, F. VESTA 3 for ThreeDimensional Visualization of Crystal, Volumetric and Morphology data. J. Appl. Crystallogr. 2011, 44, 1272-1276. 
Table of Contents artwork

1

2

3

4

5

6

7

8

9

10

11

12

13

14

15

16

17

18

19

20

21

22

23

24

25

26

27

28

29

30

31

32

33

34

35

36

37

38

39

40

41

42

43

44

45

46

47

48

49

50

51

52

53

54

55

56

57

58

59

60
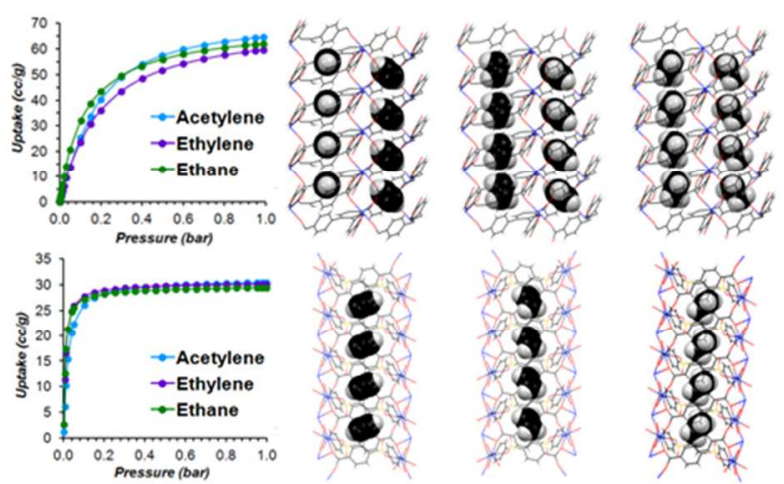